\title{
BCL-3 promotes the tumor growth of hepatocellular carcinoma by regulating cell proliferation and the cell cycle through cyclin D1
}

\author{
KANGSHENG TU ${ }^{1}$, ZHIKUI LIU ${ }^{1}$, BOWEN YAO ${ }^{1}$, YUMO XUE $^{1}$, MENG XU $^{1}$, \\ CHANGWEI DOU ${ }^{1}$, GUOZHI YIN ${ }^{1}$ and JUN WANG ${ }^{2}$ \\ Departments of ${ }^{1}$ Hepatobiliary Surgery and ${ }^{2}$ Emergency, The First Affiliated Hospital of Xi'an Jiaotong University, \\ Xi'an, Shaanxi 710061, P.R. China
}

Received December 2, 2015; Accepted December 29, 2015

DOI: $10.3892 / o r .2016 .4616$

\begin{abstract}
Previous studies have demonstrated the aberrant expression and oncogenic role of B-cell CLL/lymphoma-3 (BCL-3) in human malignancies. However, the clinical significance of BCL-3 and its biological function in human hepatocellular carcinoma (HCC) remain unknown. In the present study, the expression levels of BCL-3 protein and mRNA in 90 pairs of HCC and matched non-tumor tissues were analyzed using immunohistochemistry and reverse transcription-quantitative polymerase chain reaction (RT-qPCR). We found that the expression levels of BCL-3 protein and mRNA in HCC tissues were significantly higher than those in the matched tumor-adjacent tissues. In addition, positive expression of BCL-3 was associated with adverse clinicopathological characteristics of the HCC patients including hepatitis B virus (HBV) infection, tumor size, cirrhosis and advanced tumor-node-metastasis (TNM) stage. Moreover, HCC patients with positive expression of BCL-3 had significantly decreased 5-year overall survival and recurrence-free survival. Importantly, BCL-3 expression was an independent prognostic factor for indicating the survival of the HCC patients. Functionally, BCL-3 knockdown markedly inhibited cell viability, proliferation and cell cycle progression in HepG2 cells, while BCL-3 overexpression promoted these cellular processes in Huh7 cells. Accordingly, in vivo experiments indicated that BCL-3 knockdown prominently suppressed the tumor growth of HepG2 cells in nude mice. Mechanistically, we revealed that the expression of cyclin D1 was decreased after BCL-3 knockdown in the HepG2 cells and was increased after BCL-3 overexpression in the Huh7 cells. Cyclin D1 silencing was found to abrogate the functional effects of BCL-3 on cellular processes in Huh7 cells. Taken
\end{abstract}

Correspondence to: Dr Jun Wang, Department of Emergency, The First Affiliated Hospital of Xi'an Jiaotong University, 277 Yanta West Road, Xi'an, Shaanxi 710061, P.R. China

E-mail: wei_gang111@163.com

Key words: BCL-3, hepatocellular carcinoma, cell proliferation, cell cycle, cyclin D1 together, our data suggest that BCL-3 may serve as a promising biomarker and an effective therapeutic target of HCC.

\section{Introduction}

Hepatocellular carcinoma (HCC) is one of the most common forms of liver cancer (1) and ranks as the third-leading cause of cancer-related mortality (2). Although numerous therapeutic strategies have been employed to treat this fatal disease, the prognosis of HCC patients remains dismal with a low 5-year survival rate of $30 \%(3,4)$. The unsatisfactory prognosis of HCC largely is attributed to the lack of diagnostic biomarkers and effective therapeutic targets. Therefore, it is of great importance to elucidate the exact mechanisms of the pathogenesis of HCC, and subsequently find promising biomarkers and therapeutic targets of HCC.

B-cell CLL/lymphoma-3 (BCL-3) is an atypical member of the $\mathrm{I} \kappa \mathrm{B}$ family (5) and can bind $\mathrm{NF}-\kappa \mathrm{B}$ homodimeric complexes of $\mathrm{p} 50$ or $\mathrm{p} 52$, which switches the transcriptional properties of the homodimers from a repressive to an activating state (6). It was initially identified as a pro-oncogene in cancers of the blood, bone marrow and lymphatic system (7-9). Recently, emerging evidence suggests that BCL-3 also plays promoting roles in the development and progression of various solid tumors (10). The mRNA and protein expression levels of BCL-3 have been reported to be overexpressed in breast $(6,11)$, nasopharyngeal (12), endometrial (13) and colorectal cancer (14). Nuclear BCL-3 expression has been found to be associated with the poor prognosis of colorectal cancer patients (14). Functionally, BCL-3 was found to regulate colony formation and cell cycle progression by regulating ubiquitination-mediated degradation of c-Myc in colorectal cancer (15). In addition, together with p50, BCL-3 was found to regulate the metastasis of renal cell carcinoma in response to antiangiogenic therapy (16). Therefore, the functional role of BCL-3 in human cancers seems to be cancer-type specific. To date, the clinical significance and the exact function of BCL-3 in HCC are poorly investigated.

In the present study, we found that the expression level of BCL-3 in human HCC was significantly elevated, and the increased expression level of BCL-3 was associated with unfavorable clinical features and the poor prognosis of the HCC patients. Our in vitro and in vivo studies demonstrated that 
BCL-3 promoted the tumor growth of HCC by facilitating cell viability, proliferation and cell cycle progression. Furthermore, we found that BCL-3 exerted its roles in HCC cells by regulating the expression of cyclin D1. Our results indicated that BCL-3 is a promising biomarker of $\mathrm{HCC}$, and can potentially serve as a therapeutic target of HCC.

\section{Materials and methods}

Clinical samples and data. Clinical specimens derived from 90 patients, including 79 males and 11 females who were diagnosed with primary $\mathrm{HCC}$, were examined in the present study, after obtaining informed consent from every patient. All patients underwent surgical resection at the Department of Hepatobiliary Surgery, The First Affiliated Hospital of Xi'an Jiaotong University during January 2007 to December 2009. All patients did not receive any chemotherapy or embolization during the perioperative period. The clinicopathological data of these 90 patients are presented in Table I. All protocols were approved by the Ethics Committee of Xi'an Jiaotong University according to the Declaration of Helsinki (as revised in Tokyo 2004).

Cell lines and transfection. The human HCC cell lines, Huh7 and HepG2, were obtained from the Institute of Biochemistry and Cell Biology, Chinese Academy of Sciences, Shanghai, China, and were maintained in Dulbecco's modified Eagle's medium (DMEM) containing 10\% fetal bovine serum (FBS) (both from Gibco, Grand Island, NY, USA) with $100 \mathrm{U} / \mathrm{ml}$ penicillin and $100 \mu \mathrm{g} / \mathrm{ml}$ streptomycin (Sigma, St. Louis, MO, USA). All cells were incubated in a humidified incubator with $5 \% \mathrm{CO}_{2}$ at $37^{\circ} \mathrm{C}$.

A specific cyclin D1 siRNA [sense, 5'-r(CCA CAG AUG UGA AGU UCA U)d(TT)-3' and antisense, 5'-r(AUG AAC UUC ACA UCU GUG G)d(TT)-3'); and a non-specific duplex oligonucleotide as a negative control (sense, 5'-r(UUC UCC GAA CGU GUC ACG U)d(TT)-3' and antisense, 5'-r(ACG UGA CAC GUU CGG AGA A)d(TT)-3'] were synthesized by Sangon Biotech, Shanghai, Co., Ltd. (Shanghai, China). The siRNAs mentioned above were transfected into HCC cells using Lipofectamine 2000 following the manufacturer's instructions (Invitrogen, Carlsbad, CA, USA). BCL-3 shRNA plasmid (h) (sc-29789-SH) and control shRNA plasmid (sc-108060) were purchased from Santa Cruz Biotechnology (Santa Cruz, CA, USA). Plasmid transfection reagent (sc-108061; Santa Cruz Biotechnology) was used for shRNA transfection. Retroviral vector pMMP-BCL-3 was generated by inserting the cDNA into pMMP. Retrovirus packaging and transduction were previously described (17).

Immunohistochemical staining. Paraffin-embedded samples were cut into $4-\mu \mathrm{m}$ sections, and were deparaffinized in xylene and re-hydrated through graded ethanol. Antigen retrieval was performed in sodium citrate buffer for $15 \mathrm{~min}$ at $100^{\circ} \mathrm{C}$, and then these slices were quenched for endogenous peroxidase activity in $3 \%$ hydrogen peroxide for $10 \mathrm{~min}$. They were blocked with goat plasma at $37^{\circ} \mathrm{C}$ for $30 \mathrm{~min}$ and incubated with the BCL-3 antibody (1:100; Santa Cruz Biotechnology) at $4^{\circ} \mathrm{C}$ overnight. After incubating with the biotinylated secondary antibody (ZSGB-Bio, Beijing, China) at room temperature for $2 \mathrm{~h}$, the sections were incubated with diaminobenzidine and were counterstained with hematoxylin. The percentage of positive tumor cells or hepatocytes was graded according to the following criteria: $0,<10 \% ; 1,10-30 \% ; 2,31-50 \%$; and $3,>50 \%$.

$R N A$ extraction and reverse transcription-quantitative polymerase chain reaction ( $R T-q P C R$ ). TRIzol reagent (Invitrogen) was employed to collect the total RNA from clinical specimens following the manufacturer's protocol. RNA was reverse-transcribed into cDNA using SuperScript II reverse transcriptase (Invitrogen) and qPCR was conducted with the TaqMan Universal PCR Master mix (Applied Biosystems, Foster City, CA, USA). The expression of BCL-3 relative to a housekeeping gene, GAPDH, was measured using an ABI Prism 7700 Sequence Detector (Applied Biosystems). The following primers were used: BCL-3 primers, 5'-GAA AAC AAC AGC CTT AGC ATG GT-3' and 5'-CTG CGG AGT ACA TTT GCG-3'; and GAPDH primers, 5'-CAA GCT CAT TTC CTG GTA TGA C-3' and 5'-CAG TGA GGG TCT CTC TCT TCC T-3'.

Protein extraction and western blot analysis. After washing twice with cold phosphate-buffered saline (PBS), total proteins were extracted from HCC cells using ice-cold modified radioimmunoprecipitation assay (RIPA) buffer (50 mM Tris- $\mathrm{HCl} \mathrm{pH} 7.4,1 \%$ Nonidet $\mathrm{P}-40,0.25 \%$ sodium deoxycholate, $150 \mathrm{mM} \mathrm{NaCl}, 1 \mathrm{mM} \mathrm{Na}_{3} \mathrm{VO}_{4}$ and $1 \mathrm{mM} \mathrm{NaF}$ ). Protein lysates $(30 \mu \mathrm{g})$ were separated by sodium dodecyl sulfate-polyacrylamide gel electrophoresis (SDS-PAGE) and transferred to NC membranes (Millipore Corporation, USA). The membranes were incubated overnight with reverse transcription-quantitative polymerase chain reaction (RT-qPCR) following primary antibodies: BCL-3 (1:200), cyclin D1 (1:500) (both from Santa Cruz Biotechnology) and GAPDH (1:1,000; US Biological, Swampscott, MA, USA). Then, the blots were incubated with peroxidase-conjugated secondary antibodies (1:2,000-1:5,000; Bio-Rad, Hercules, CA, USA), and visualized with the ECL system (Amersham, Piscataway, NJ, USA).

Cell viability assay. $\mathrm{HCC}$ cells at the log-phase of growth were seeded into 96 -well plates at $2 \times 10^{3}$ cells/well. A solution (50 $\mu \mathrm{l})$ of 3-(4,5-dimethylthiazol-2-yl)-2,5-diphenyl tetrazolium bromide (MTT; Roche, USA) (5 mg/ml; KeyGen, China) was added into each well at 24,48 and $72 \mathrm{~h}$ after transfection. Four hours later, the supernatant was removed, and $200 \mu \mathrm{l}$ of dimethyl sulfoxide (DMSO) was added to each well. Optical density (OD) was measured at $490 \mathrm{~nm}$ to represent the viability of the HCC cells.

Cell cycle assay. Forty-eight hours after transfection, the cells were washed with cold PBS twice, and were fixed with $70 \%$ ethanol at $4^{\circ} \mathrm{C}$ overnight. After extensive washing, the cells were incubated with $50 \mu \mathrm{g} / \mathrm{ml}$ PI and $50 \mu \mathrm{g} / \mathrm{ml}$ RNase A for $1 \mathrm{~h}$ at room temperature. After incubation, the cells were subjected to flow cytometric analysis using a FACSCalibur (BD Biosciences, Bedford, MA, USA). Experiments were performed in triplicate. The results are presented as the percentage (\%) of cells in a particular phase. 
In vivo experiments. The nude mouse xenograft model was established using 4- to 6-week-old female BALB/c nude mice (Centre of Laboratory Animals, The Medical College of Xi'an Jiaotong University, Xi'an, China). HepG2 cells $\left(4 \times 10^{6}\right)$ transfected with BCL-3 shRNA or NT shRNA were mixed in $150 \mu \mathrm{l}$ PBS, and were subcutaneously injected into the flank of each mouse. Tumor growth curves were generated as previously described (18). All animal protocols were approved by the Institutional Animal Care and Use Committee of Xi'an Jiaotong University.

Statistical analysis. All statistical analyses were performed using the SPSS Statistical Package for Windows version 13 (SPSS, Inc., Chicago, IL, USA) or GraphPad Prism 5 software (GraphPad Software, Inc., San Diego, CA, USA). The quantitative data were compared between groups using the Student's t-test or ANOVA. Categorical data were analyzed using the Pearson's Chi-square test. The Kaplan-Meier method and log-rank test were used to compare the cumulative recurrence and survival rates. The independent factors influencing the survival and recurrence of HCC patients were determined using the Cox proportional hazards model. A value of $\mathrm{P}<0.05$ was considered to indicate a statistically significant result.

\section{Results}

Expression of BCL-3 is elevated in HCC tissues. Immunohistochemical staining was first performed to explore the difference in BCL-3 expression between the HCC and adjacent non-tumor tissues. BCL-3 expression was considered as either negative (scores $0-1$ ) or positive (scores 2-3). BCL-3 expression was detected in $64.4 \%$ (58/90) of the HCC specimens, whereas only $23.3 \%$ (21/90) of the non-cancerous tissues showed a positive BCL-3 signal ( $\mathrm{P}<0.05$; Fig. 1). Furthermore, the results of IHC scores showed that the level of BCL-3 expression in HCC tissues was significantly elevated compared with that in the adjacent non-tumor tissues $(\mathrm{P}<0.05$; Fig. 2A). To further confirm the results of IHC staining, we performed RT-qPCR to examine the mRNA level of BCL-3 in the clinical tissues. The results of RT-qPCR showed that the BCL-3 mRNA level in the HCC tissues was also significantly elevated compared to that in the non-tumor tissues $(\mathrm{P}<0.05$; Fig. 2B). Taken together, these results suggest that BCL-3 plays an oncogenic role in the pathogenesis of HCC.

Positive expression of BCL-3 is correlated with adverse clinicopathological features and poor prognosis of HCC patients. To further determine the clinical significance and prognostic value of BCL-3 in HCC, we first divided the patients into two groups based on the staining of BCL-3 in HCC tissues (positive group, $n=58$; negative group, $n=32$ ). Then, we compared the clinicopathological features between patients in these two groups. As shown in Table I, positive expression of BCL-3 was associated with hepatitis B virus (HBV) infection $(\mathrm{P}=0.015)$, tumor size $(\mathrm{P}=0.005)$, cirrhosis $(\mathrm{P}=0.018)$ and TNM tumor stage $(\mathrm{P}=0.035)$. Furthermore, we compared the overall survival (OS) and recurrence-free survival (RFS) between patients in these two groups. Kaplan-Meier survival curves showed that patients with positive staining of BCL-3 had significantly reduced OS $(\mathrm{P}=0.0392$; Fig. $2 \mathrm{C})$ and $\mathrm{RFS}$
Table I. Clinicopathological correlation of BCL-3 expression in the HCC cases.

\begin{tabular}{|c|c|c|c|c|}
\hline \multirow[b]{2}{*}{$\begin{array}{l}\text { Clinicopathological } \\
\text { features }\end{array}$} & \multirow[b]{2}{*}{$\mathrm{n}$} & \multicolumn{2}{|c|}{ BCL-3 expression } & \multirow[b]{2}{*}{ P-value } \\
\hline & & $\begin{array}{l}\text { Positive } \\
(\mathrm{n}=58)\end{array}$ & $\begin{array}{l}\text { Negative } \\
(n=32)\end{array}$ & \\
\hline Age (years) & & & & 0.323 \\
\hline$\leq 50$ & 36 & 21 & 15 & \\
\hline$>50$ & 54 & 37 & 17 & \\
\hline Gender & & & & 0.692 \\
\hline Male & 79 & 52 & 27 & \\
\hline Female & 11 & 6 & 5 & \\
\hline HBV infection & & & & $0.015^{\mathrm{a}}$ \\
\hline No & 13 & 4 & 9 & \\
\hline Yes & 77 & 54 & 23 & \\
\hline Serum AFP level (ng/ml) & & & & 0.102 \\
\hline$\leq 20$ & 27 & 14 & 13 & \\
\hline$>20$ & 63 & 44 & 19 & \\
\hline Tumor size (cm) & & & & $0.005^{\mathrm{a}}$ \\
\hline$\leq 5$ & 41 & 20 & 21 & \\
\hline$>5$ & 49 & 38 & 11 & \\
\hline No. of tumor nodules & & & & 0.183 \\
\hline 1 & 74 & 50 & 24 & \\
\hline$\geq 2$ & 16 & 8 & 8 & \\
\hline Cirrhosis & & & & $0.018^{\mathrm{a}}$ \\
\hline Absent & 21 & 9 & 12 & \\
\hline Present & 69 & 49 & 20 & \\
\hline Venous infiltration & & & & 0.293 \\
\hline Absent & 43 & 25 & 18 & \\
\hline Present & 47 & 33 & 15 & \\
\hline Edmondson-Steiner grade & & & & 0.264 \\
\hline $\mathrm{I}+\mathrm{II}$ & 68 & 46 & 22 & \\
\hline III+IV & 22 & 12 & 10 & \\
\hline TNM tumor stage & & & & $0.035^{\mathrm{a}}$ \\
\hline $\mathrm{I}+\mathrm{II}$ & 67 & 39 & 28 & \\
\hline $\mathrm{III}+\mathrm{IV}$ & 23 & 19 & 4 & \\
\hline
\end{tabular}

HCC, hepatocellular carcinoma; HBV, hepatitis B virus; AFP,

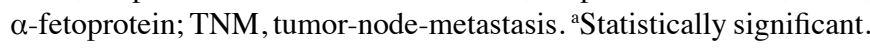

$(\mathrm{P}=0.0445$; Fig. 2D). These data suggest that BCL-3 may be involved in the development and progression of $\mathrm{HCC}$, and can serve as a promising predictor of the prognosis of $\mathrm{HCC}$ patients. Furthermore, multivariate Cox regression analysis indicated that BCL-3 expression was an independent factor for predicting both 5-year OS and RFS in HCC patients $(\mathrm{P}=0.016$ and 0.009, respectively; Table II).

BCL-3 promotes the growth of HCC cells both in vitro and in vivo. To explore the functional role of BCL-3 in HCC, a BCL-3-specific shRNA was employed to suppress the expression of BCL-3 in HepG2 cells. Western blotting was used to confirm the knockdown of BCL-3 ( $\mathrm{P}<0.05$; Fig. 3A). 


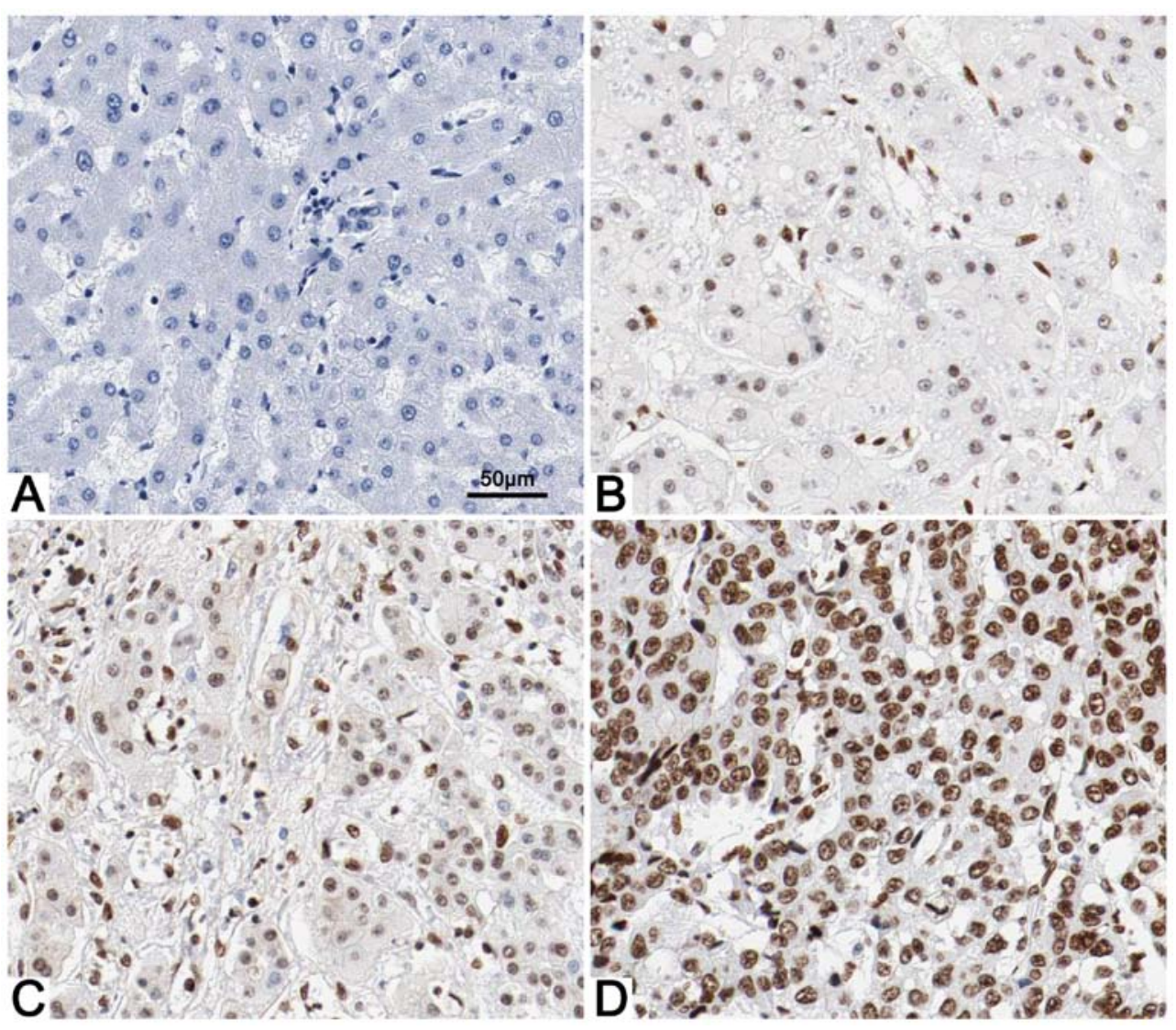

Figure 1. Representative immunohistochemical staining of BCL-3 in tumor-adjacent and HCC tissues. (A) Negative staining of BCL-3 in adjacent non-tumor tissue. (B) Low, (C) medium and (D) high expression of BCL-3 in HCC tissues. Scale bar, $50 \mu \mathrm{m}$.

A

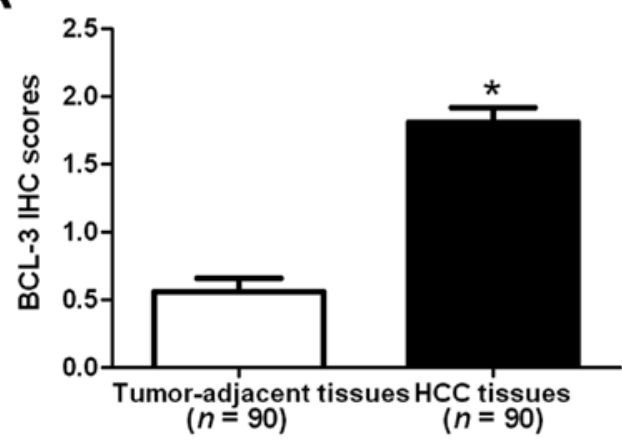

C

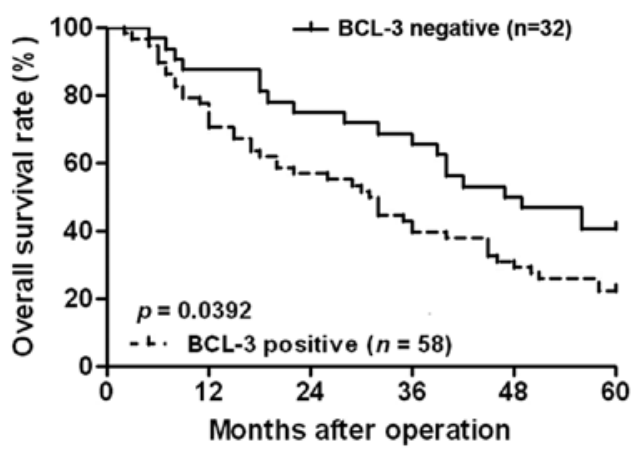

B

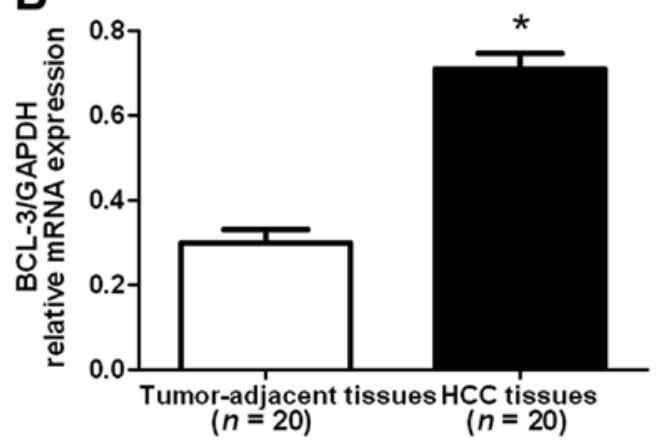

D

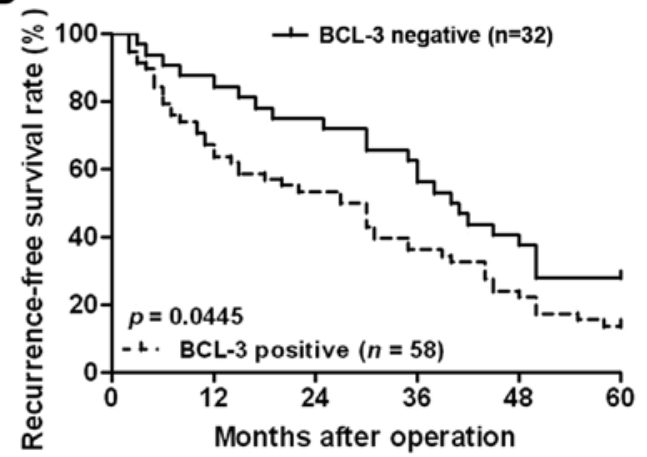

Figure 2. Expression status and prognostic significance of BCL-3 in HCC. (A) Comparison of the differences in the protein levels of BCL-3 between HCC and tumor adjacent tissues. " $\mathrm{P}<0.05$ by t-test. (B) RT-qPCR showed that the mRNA level of BCL-3 in HCC tissues was significantly elevated compared with that in adjacent non-tumor tissues. "P<0.05 by t-test. (C and D) Patients with positive expression of BCL-3 had significantly decreased overall survival and recurrence-free survival. 
Table II. Multivariate Cox regression analysis of the 5-year survival of $90 \mathrm{HCC}$ patients.

\begin{tabular}{|c|c|c|c|c|c|c|}
\hline \multirow[b]{2}{*}{ Variables } & \multicolumn{3}{|c|}{ OS } & \multicolumn{3}{|c|}{ RFS } \\
\hline & HR & $95 \% \mathrm{CI}$ & P-value & HR & $95 \% \mathrm{CI}$ & P-value \\
\hline HBV infection & 1.26 & $0.93-1.70$ & 0.143 & 1.19 & $0.81-1.75$ & 0.367 \\
\hline Tumor size & 1.41 & $1.05-1.88$ & $0.022^{\mathrm{a}}$ & 1.13 & $0.83-1.55$ & 0.431 \\
\hline Cirrhosis & 1.29 & $0.94-1.76$ & 0.120 & 1.18 & $0.86-1.63$ & 0.303 \\
\hline TNM tumor stage & 1.65 & $1.20-2.27$ & $0.002^{\mathrm{a}}$ & 1.57 & $1.14-2.10$ & $0.006^{\mathrm{a}}$ \\
\hline BCL-3 expression & 1.58 & $1.09-2.29$ & $0.016^{\mathrm{a}}$ & 1.48 & $1.10-1.98$ & $0.009^{\mathrm{a}}$ \\
\hline
\end{tabular}

OS, overall survival; RFS, recurrence-free survival; HCC, hepatocellular carcinoma; HBV, hepatitis B virus; TNM, tumor-node-metastasis; HR, hazard ratio; CI, confidence interval. a Statistically significant.
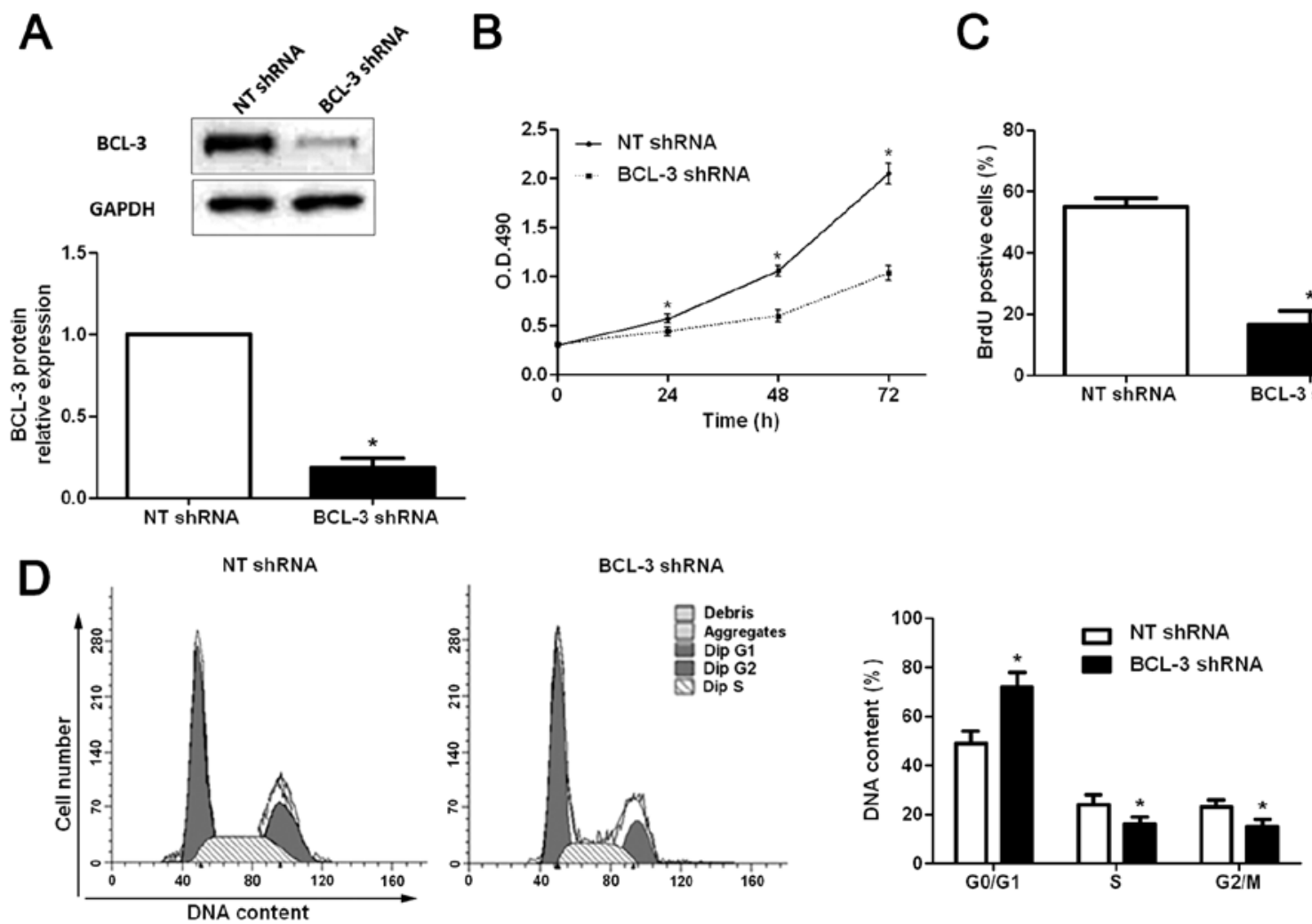

Figure 3. Suppression of BCL-3 expression inhibits the cell viability, proliferation and cell cycle progression in HepG2 cells. (A) BCL-3-specific shRNA significantly inhibited the levels of BCL-3 protein in the HepG2 cells. $n=3$ independent experiments. " $P<0.05$ by t-test. (B) Cell viability of HepG2 cells as assessed by MTT assays was suppressed by BCL- 3 silencing. $n=3$ independent experiments. " $\mathrm{P}<0.05$ by ANOVA. (C) Cell proliferation as assessed by BrdU incorporation was inhibited after BCL-3 knockdown. $\mathrm{n}=3$ independent experiments. ${ }^{*} \mathrm{P}<0.05$ by $\mathrm{t}$-test. (D) Cell cycle assays demonstrated that BCL-3 knockdown increased the percentage of HepG2 cells in the G0/G1 phase while decreased the percentage of HepG2 cells in the $\mathrm{S}$ and G2/M phase. $\mathrm{n}=3$ independent repeats with similar results. ${ }^{*} \mathrm{P}<0.05$ by t-test.

Subsequently, the results of the MTT assays showed that the viability of the HepG2 cells was significantly decreased after BCL-3 knockdown ( $\mathrm{P}<0.05$; Fig. 3B). The proliferation of HepG2 cells was significantly decreased following BCL-3 downregulation $(\mathrm{P}<0.05$; Fig. 3C), as determined by BrdU incorporation assays. In addition, cell cycle assays showed that knockdown of BCL-3 significantly increased the percentage of cells in the $G 0 / G 1$ phase $(\mathrm{P}<0.05)$, and decreased the percentage of cells in the $S$ phase $(\mathrm{P}<0.05)$ and $\mathrm{G} 2 / \mathrm{M}$ phase $(\mathrm{P}<0.05)$ (Fig. 3D). In contrast, the BCL-3-overexpressing plasmid obviously upregulated the expression of BCL-3 in the Huh7 cells $(\mathrm{P}<0.05$; Fig. 4A), and resulted in significantly increased cell viability $(\mathrm{P}<0.05$; Fig. 4B), proliferation $(\mathrm{P}<0.05$; Fig. $4 \mathrm{C})$ and cell cycle progression ( $\mathrm{P}<0.05$; Fig. 4D). These data suggest that BCL-3 promotes the growth of HCC cells by regulating cell viability, proliferation and cell cycle progression in vitro.

To further confirm the promoting effects of BCL-3 on HCC cell growth in vivo, we subcutaneously injected HepG2 cells transfected with scramble shRNA or BCL-3 shRNA into nude mice. As shown in Fig. 5A, BCL-3 knockdown 

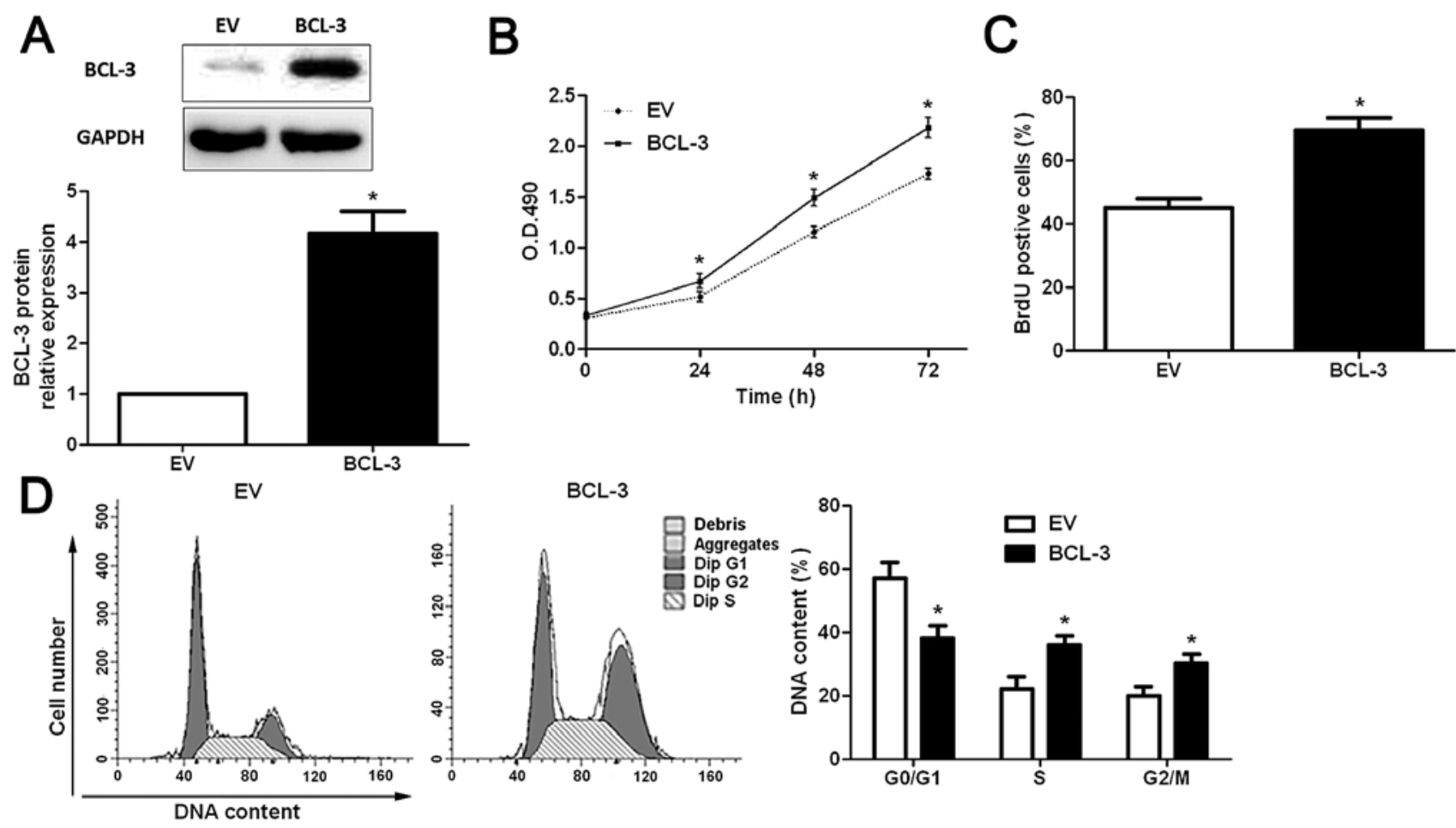

Figure 4. Forced expression of BCL-3 promotes the cell viability, proliferation and cell cycle progression of Huh7 cells. (A) A BCL-3-expressing vector significantly upregulated the levels of BCL-3 protein in the Huh7 cells; $n=3$ independent experiments; " $\mathrm{P}<0.05$ by t-test. (B) Cell viability of Huh7 cells as assessed by MTT assays was promoted after BCL-3 overexpression. $\mathrm{n}=3$ independent experiments; ${ }^{\mathrm{P}}<0.05$ by ANOVA. (C) Cell proliferation as assessed by BrdU incorporation was increased after BCL-3 overexpression. $\mathrm{n}=3$ independent experiments; ${ }^{*} \mathrm{P}<0.05$ by $\mathrm{t}$-test. (D) Cell cycle assays demonstrated that BCL-3 overexpression increased the percentage of Huh7 cells in the G0/G1 phase while increased the percentage of Huh7 cells in the S and G2/M phase. n=3 independent repeats with similar results; ${ }^{*} \mathrm{P}<0.05$ by t-test.
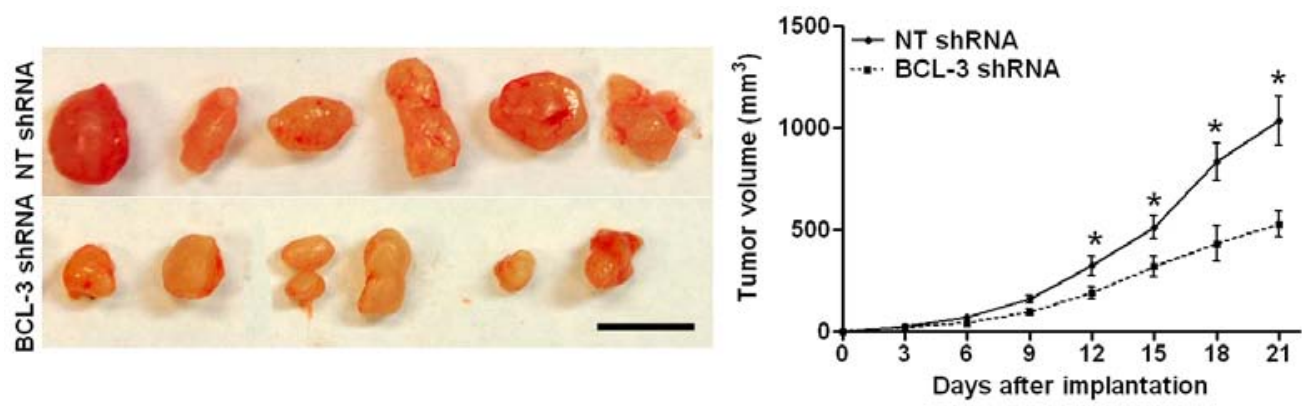

Figure 5. BCL-3 knockdown suppresses tumor growth in nude mice. HepG2 cells transfected with BCL-3 shRNA or NT shRNA were injected subcutaneously into nude mice. Tumor growth curves showed that HepG2 cells with BCL-3 knockdown $(n=6)$ had a significant slower growth as compared with that of the control cells $(\mathrm{n}=6) ;{ }^{*} \mathrm{P}<0.05$ by ANOVA. Scale bar, $1 \mathrm{~cm}$.

significantly inhibited the growth of the HepG2 cells in nude mice $(\mathrm{P}<0.05)$. Taken together, these data suggest that BCL-3 promotes the growth of $\mathrm{HCC}$ cells both in vitro and in vivo.

$B C L-3$ regulates the expression of cyclin Dl in $H C C$ cells. Cyclin D1 has been found to be overexpressed in HCC $(19,20)$, and plays an important role in regulating cell cycle progression (21). Therefore, we ascertained whether BCL-3 regulates the expression of cyclin D1 in HCC cells. The results of the western blot analyses showed that the expression of cyclin D1 was significantly reduced after downregulation of the expression of BCL-3 ( $\mathrm{P}<0.05$; Fig. 6A). In contrast, overexpression of BCL-3 resulted in a significant increase in cyclin D1 expression $(\mathrm{P}<0.05$, Fig. 6B). These data indicate that BCL-3 regulates the expression of cyclin D1 in HCC cells.

Cyclin D1 mediates the functional effects of BCL-3 in HCC cells. To further determine whether cyclin D1 is a functional mediator of BCL-3, we inhibited cyclin D1 expression in the BCL-3-overexpressing Huh7 cells using cyclin D1-specific siRNA. Cyclin D1 siRNA significantly inhibited the expression of cyclin D1 $(\mathrm{P}<0.05$; Fig. 7A) in the BCL-3-overexpressing Huh7 cells while it had no influence on the expression of BCL-3 (Fig. 7A). Functionally, 

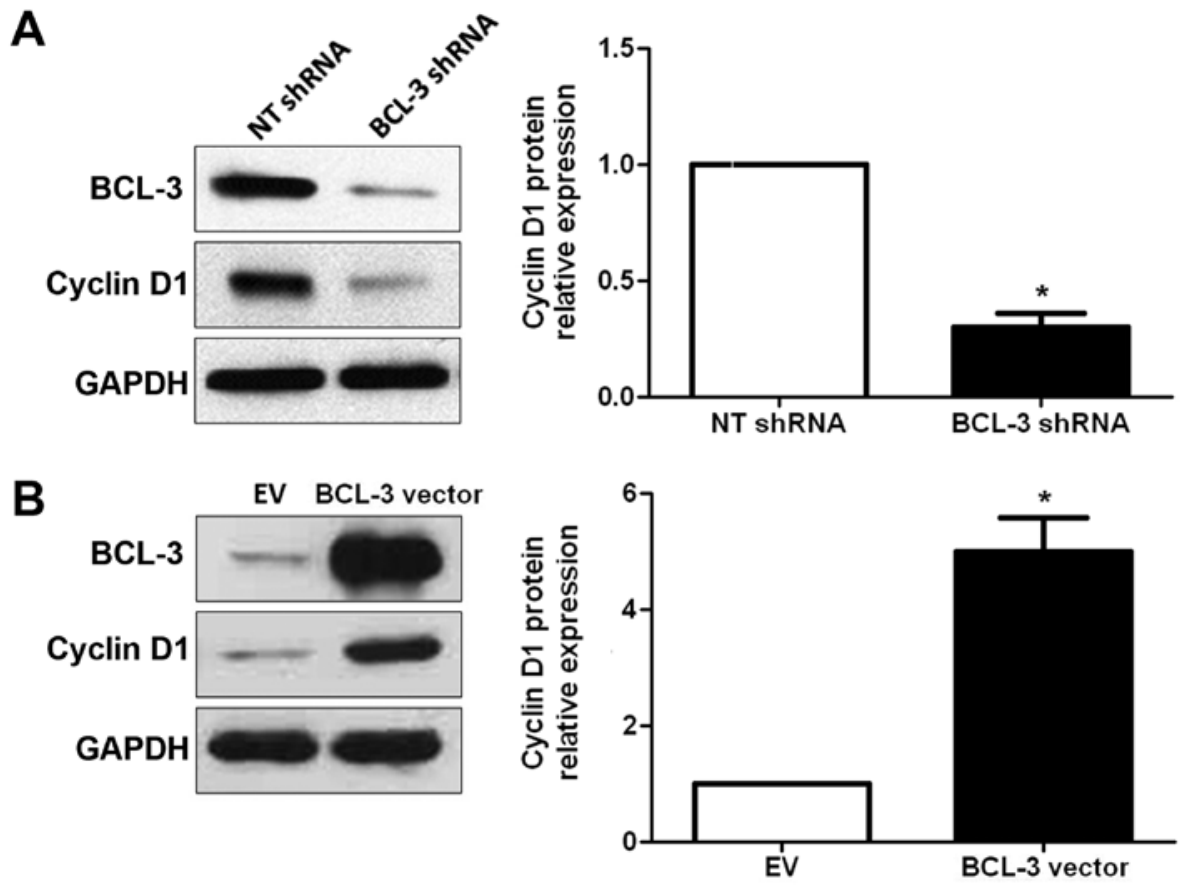

Figure 6. BCL-3 regulates the expression of cyclin D1 in HCC cells. (A) BCL-3 knockdown in HepG2 cells significantly reduced the protein level of cyclin D1. $\mathrm{n}=3$ independent repeats with similar results; ${ }^{*} \mathrm{P}<0.05$ by t-test. (B) Overexpression of BCL-3 obviously increased the expression of cyclin D1 protein in Huh7 cells. $\mathrm{n}=3$ independent repeats with similar results; ${ }^{*} \mathrm{P}<0.05$ by $\mathrm{t}$-test.
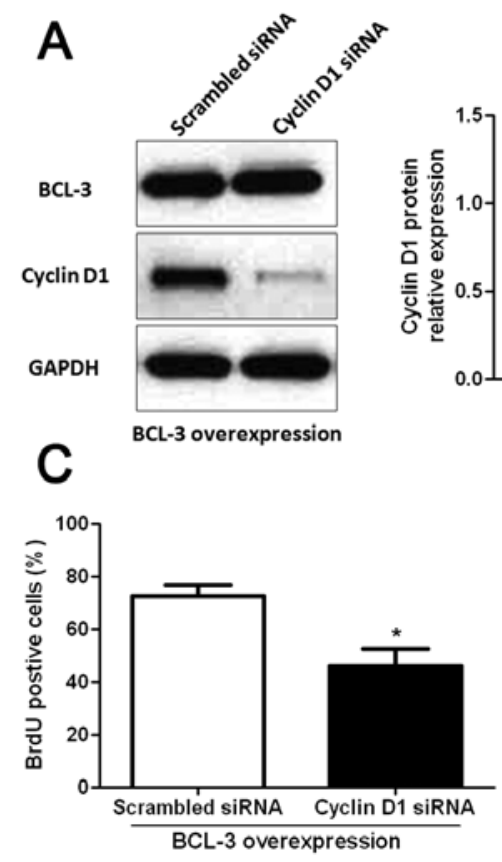
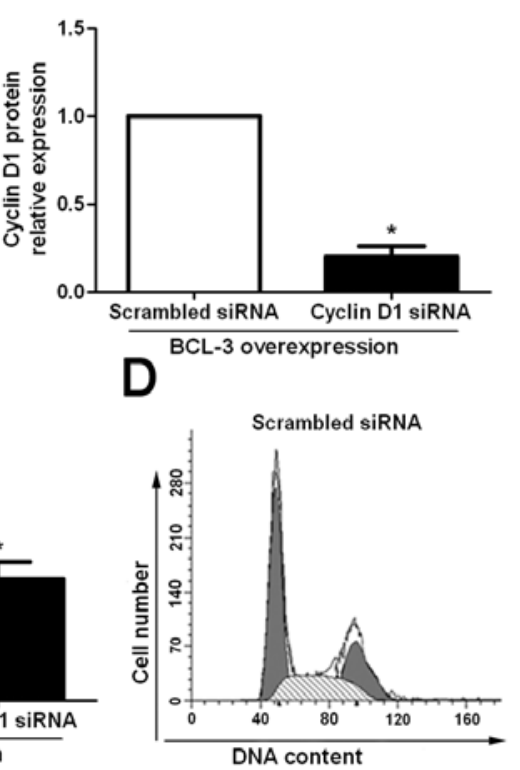

B

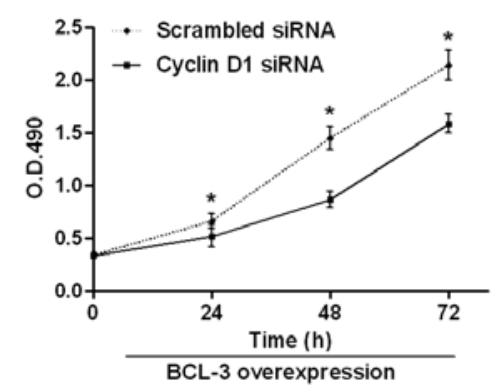

Cyclin D1 siRNA

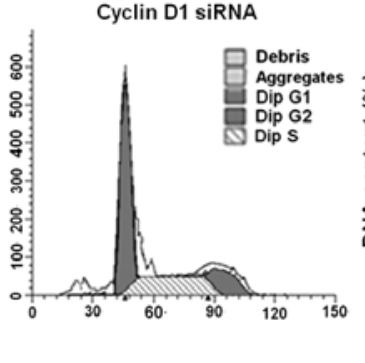

Figure 7. Inhibition of cyclin D1 expression abrogates the effect of BCL-3 on Huh7 cells. (A) Cyclin D1-specific siRNA significantly inhibited the expression of cyclin D1 while had no influence on BCL-3 in the BCL-3-overexpressing Huh7 cells. $n=3$ repeats with similar results; ${ }^{*} \mathrm{P}<0.05$ by $\mathrm{t}$-test. Inhibition of cyclin D1 expression abolished the functional effect of BCL-3 on (B) cell viability, (C) proliferation and (D) cell cycle progression. $\mathrm{n}=3$ repeats with similar results; ${ }^{*} \mathrm{P}<0.05$ by ANOVA (MTT assay) and t-test (BrdU incorporation and cell cycle assays).

inhibition of cyclin D1 partially abrogated the effect of BCL-3 overexpression, resulting in a significant decrease in cell viability $(\mathrm{P}<0.05$; Fig. 7B) and proliferation $(\mathrm{P}<0.05$; Fig. 7C), and cell cycle arrest $(\mathrm{P}<0.05$; Fig. 7D). These results demonstrated that cyclin $\mathrm{D} 1$ is a downstream mediator of the biological function of BCL-3 in HCC.

\section{Discussion}

Treatment of HCC, particularly for patients in an advanced stage, is still a challenge for physicians (22). In addition, the long-term prognosis for HCC patients is still dismal (23). Therefore, it is of great importance to identify novel biomarkers and effective 
therapeutic targets, which may promote the early diagnosis and improve the efficacy of molecular-targeted drugs for HCC. In the present study, we examined the expression status of BCL-3 in HCC tissues for the first time. In addition, we found that, compared with adjacent non-tumor tissues, HCC tissues harbored significantly higher expression of BCL-3 at both the mRNA and protein levels. Importantly, positive expression of BCL-3 was associated with poor clinicopathological features and reduced survival of HCC patients. Notably, HCC patients with $\mathrm{HBV}$ infection and cirrhosis showed significantly higher levels of BCL-3 expression. Herein, previous studies of hepatocarcinogenesis indicated that $\mathrm{HBx}$ protein upregulated the expression of BCL-3 mRNA, which subsequently resulted in the upregulation of the NF- $\kappa \mathrm{B} 2$ (p52)/BCL-3 complex in the nucleus (24). Therefore, these results suggest that BCL-3 can potentially serve as a promising biomarker for the early diagnosis and is a valuable predictor of the prognosis of HCC patients.

The significant elevation of BCL-3 expression in HCC tissues and its association with clinicopathological features and prognosis of $\mathrm{HCC}$ patients, suggests a potential oncogenic role of BCL-3 in $\mathrm{HCC}$, and motivated us to explore its functional significance in HCC. Previous studies have found that BCL-3 promotes the survival and inhibits the apoptosis of colorectal cancer cells (25). In addition, BCL-3 was found to be involved in the response to antiangiogenic therapy in a mouse model of metastatic renal cell carcinoma (16). In the present study, the in vitro studies demonstrated that BCL-3 knockdown inhibited cell viability, proliferation and cell cycle progression of HepG2 cells while its overexpression had promoting effects on these biological behaviors in the Huh7 cells. In addition, in vivo experiments showed that BCL-3 downregulation inhibited the growth of HepG2 cells in nude mice. Therefore, our data revealed that BCL-3 contributes to the growth of HCC by promoting cell viability, proliferation and cell cycle progression.

Cyclin D1, a downstream mediator of the PI3K/GSK-3 signaling pathway, functions as a well-recognized regulator of cell cycle progression and proliferation, and has been found to be deregulated in many types of human cancers, including HCC $(26,27)$. In the present study, we confirmed that BCL-3 regulated the expression of cyclin D1 in HCC cells using knockdown and overexpression assays. Furthermore, we demonstrated that inhibition of cyclin D1 expression in Huh7 cells overexpressing BCL-3 abrogated the functional influence of BCL-3 on Huh7 cells, suggesting that BCL-3 not only regulated the expression of cyclin D1, but also exerted its biological functions in HCC through cyclin D1. Notably, a study of prostate cancer showed that BCL-3 regulated the chemotherapeutic drug-induced apoptosis by modulating the expression of Id-1 and Id-2 proteins (28). In addition, BCL-3 was found to stabilize the expression CtBP1 by inhibiting proteasome-dependent degradation, thus leading to increased resistance of breast cancer cells to apoptosis (11). Therefore, the functional role of BCL-3 in human cancers and the underlying mechanisms by which BCL-3 exerts its functional influence are largely dependent on the cancer type.

In summary, the present study confirmed for the first time that BCL-3 is overexpressed in HCC tissues. Patients with positive expression of BCL-3 had adverse clinicopathological features and poorer prognosis. Functionally, BCL-3 can promote the growth of $\mathrm{HCC}$ cells by promoting cell viability, proliferation and cell cycle progression. Furthermore, BCL-3 can regulate the expression of cyclin D1 in HCC cells, and its functional influence on HCC cells is realized through cyclin D1. Therefore, the present study demonstrated that BCL-3 can serve as a promising biomarker for the early diagnosis and prognostic prediction of HCC patients, and can potentially act as an effective therapeutic target of HCC.

\section{Acknowledgements}

The present study was supported by a grant from the National Natural Science Foundation of China (no. 81402039).

\section{References}

1. Ferlay J, Shin HR, Bray F, Forman D, Mathers C and Parkin DM: Estimates of worldwide burden of cancer in 2008: GLOBOCAN 2008. Int J Cancer 127: 2893-2917, 2010.

2. Forner A, Llovet JM and Bruix J: Hepatocellular carcinoma. Lancet 379: 1245-1255, 2012.

3. Kim SH, Choi SB, Lee JG, Kim SU, Park MS, Kim do Y, Choi JS and Kim KS: Prognostic factors and 10-year survival in patients with hepatocellular carcinoma after curative hepatectomy. J Gastrointest Surg 15: 598-607, 2011.

4. Hanazaki K, Kajikawa S, Shimozawa N, Mihara M, Shimada K, Hiraguri M, Koide N, Adachi W and Amano J: Survival and recurrence after hepatic resection of 386 consecutive patients with hepatocellular carcinoma. J Am Coll Surg 191: 381-388, 2000.

5. Bours V, Franzoso G, Azarenko V, Park S, Kanno T, Brown K and Siebenlist U: The oncoprotein Bcl-3 directly transactivates through kappa B motifs via association with DNA-binding p50B homodimers. Cell 72: 729-739, 1993.

6. Cogswell PC, Guttridge DC, Funkhouser WK and Baldwin AS Jr: Selective activation of NF-kappa B subunits in human breast cancer: Potential roles for NF-kappa B2/p52 and for Bcl-3. Oncogene 19: 1123-1131, 2000.

7. Au WY, Horsman DE, Ohno H, Klasa RJ and Gascoyne RD: Bcl-3/IgH translocation $(14 ; 19)(\mathrm{q} 32 ; \mathrm{q} 13)$ in non-Hodgkin's lymphomas. Leuk Lymphoma 43: 813-816, 2002.

8. Canoz O, Rassidakis GZ, Admirand JH and Medeiros LJ: Immunohistochemical detection of BCL-3 in lymphoid neoplasms: A survey of 353 cases. Mod Pathol 17: 911-917, 2004.

9. Schlette E, Rassidakis GZ, Canoz O and Medeiros LJ: Expression of bcl-3 in chronic lymphocytic leukemia correlates with trisomy 12 and abnormalities of chromosome 19. Am J Clin Pathol 123: 465-471, 2005.

10. Maldonado V and Melendez-Zajgla J: Role of Bcl-3 in solid tumors. Mol Cancer 10: 152, 2011.

11. Choi HJ, Lee JM, Kim H, Nam HJ, Shin HJ, Kim D, Ko E, Noh DY, Kim KI, Kim JH, et al: Bcl3-dependent stabilization of CtBP1 is crucial for the inhibition of apoptosis and tumor progression in breast cancer. Biochem Biophys Res Commun 400: 396-402, 2010.

12. Thornburg NJ, Pathmanathan R and Raab-Traub N: Activation of nuclear factor-kappaB p50 homodimer/Bcl-3 complexes in nasopharyngeal carcinoma. Cancer Res 63: 8293-8301, 2003.

13. Pallares J, Martínez-Guitarte JL, Dolcet X, Llobet D, Rue M, Palacios J, Prat $\mathbf{J}$ and Matias-Guiu X: Abnormalities in the NF-kappaB family and related proteins in endometrial carcinoma. J Pathol 204: 569-577, 2004.

14. Puvvada SD, Funkhouser WK, Greene K, Deal A, Chu H, Baldwin AS, Tepper JE and O'Neil BH: NF- $\kappa$ B and Bcl-3 activation are prognostic in metastatic colorectal cancer. Oncology 78: 181-188, 2010.

15. Liu Z, Jiang Y, Hou Y, Hu Y, Cao X, Tao Y, Xu C, Liu S, Wang S, Wang L, et al: The IкB family member Bcl-3 stabilizes c-Myc in colorectal cancer. J Mol Cell Biol 5: 280-282, 2013.

16. de Souza Braga M, da Silva Paiva KB, Foguer K, Barbosa Chaves KC, de Sá Lima L, Scavone C and Bellini MH: Involvement of the NF- $\kappa \mathrm{B} / \mathrm{p} 50 / \mathrm{Bcl}-3$ complex in response to antiangiogenic therapy in a mouse model of metastatic renal cell carcinoma. Biomed Pharmacother 68: 873-879, 2014. 
17. Tu K, Yang W, Li C, Zheng X, Lu Z, Guo C, Yao Y, Liu Q: Fbxw7 is an independent prognostic marker and induces apoptosis and growth arrest by regulating YAP abundance in hepatocellular carcinoma. Mol Cancer 13: 110, 2014

18. Dou C, Wang Y, Li C, Liu Z, Jia Y, Li Q, Yang W, Yao Y, Liu Q and Tu K: MicroRNA-212 suppresses tumor growth of human hepatocellular carcinoma by targeting FOXA1. Oncotarget 6 : 13216-13228, 2015.

19. Deane NG, Parker MA, Aramandla R, Diehl L, Lee WJ, Washington MK, Nanney LB, Shyr Y and Beauchamp RD: Hepatocellular carcinoma results from chronic cyclin D1 overexpression in transgenic mice. Cancer Res 61: 5389-5395, 2001.

20. Joo M, Kang YK, Kim MR, Lee HK and Jang JJ: Cyclin D1 overexpression in hepatocellular carcinoma. Liver 21: 89-95, 2001.

21. Stacey DW: Cyclin D1 serves as a cell cycle regulatory switch in actively proliferating cells. Curr Opin Cell Biol 15: 158-163, 2003.

22. Severi T, van Malenstein H, Verslype $\mathrm{C}$ and van Pelt JF: Tumor initiation and progression in hepatocellular carcinoma: Risk factors, classification, and therapeutic targets. Acta Pharmacol Sin 31: 1409-1420, 2010.

23. Sun VC and Sarna L: Symptom management in hepatocellular carcinoma. Clin J Oncol Nurs 12: 759-766, 2008.
24. Park SG, Chung C, Kang H, Kim JY and Jung G: Up-regulation of cyclin D1 by HBx is mediated by NF-kappaB2/BCL3 complex through kappaB site of cyclin D1 promoter. J Biol Chem 281: 31770-31777, 2006.

25. Urban BC, Collard TJ, Eagle CJ, Southern SL, Greenhough A, Hamdollah-Zadeh M, Ghosh A, Poulsom R, Paraskeva C, Silver A, et al: BCL-3 expression promotes colorectal tumorigenesis through activation of AKT signalling. Gut: Jun 1, 2015 (Epub ahead of print). pii: gutjnl-2014-308270. doi: 10.1136/gutjnl2014-308270.

26. Freiburghaus C, Janicke B, Lindmark-Månsson H, Oredsson SM and Paulsson MA: Lactoferricin treatment decreases the rate of cell proliferation of a human colon cancer cell line. J Dairy Sci 92: 2477-2484, 2009.

27. Zwijsen RM, Klompmaker R, Wientjens EB, Kristel PM, van der Burg B and Michalides RJ: Cyclin D1 triggers autonomous growth of breast cancer cells by governing cell cycle exit. Mol Cell Biol 16: 2554-2560, 1996.

28. Ahlqvist K, Saamarthy K, Syed Khaja AS, Bjartell A and Massoumi R: Expression of Id proteins is regulated by the Bcl-3 proto-oncogene in prostate cancer. Oncogene 32: 1601-1608, 2013. 